\title{
Sveikiname Lietuvą
}

Écrit par : Balázs Gyimesi, L'Observateur de l'OCDE

Dernière mise à jour : 10 juillet 2018

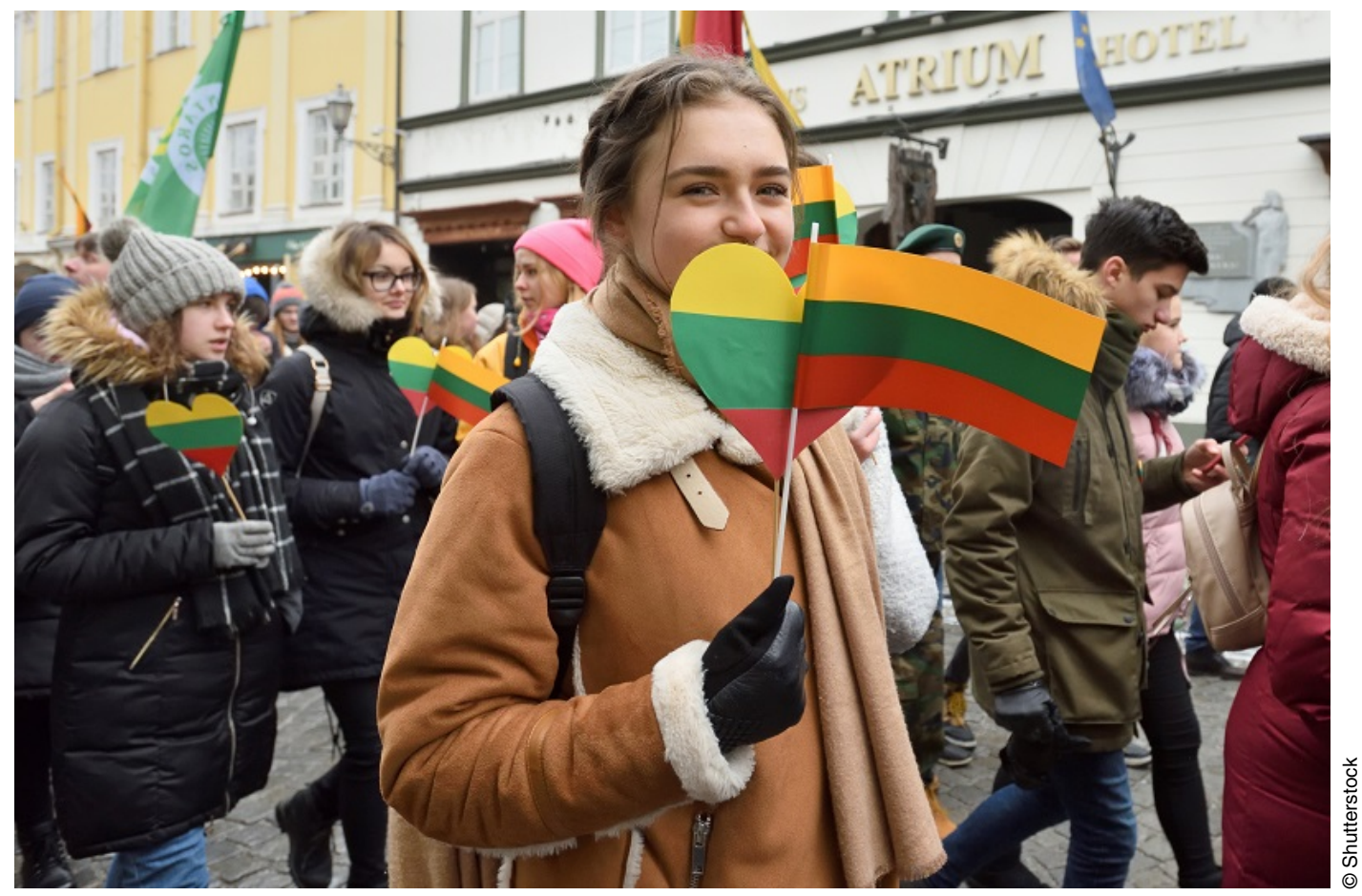

Sveikiname Lietuvą : Bienvenue à l'OCDE, Lituanie ! Le pays balte est devenu le 36e membre de l'Organisation le 5 juillet 2018, soit la veille de la fête nationale qui commémore le couronnement du premier roi de Lituanie, Mindaugas, en 1253. La Lituanie est la troisième république balte à rejoindre l'OCDE, après l'Estonie (2010) et la Lettonie (2016). Également membre de l'UE, de l'OTAN et de plusieurs autres organisations multilatérales, la Lituanie compte 3,1 millions d'habitants, a pour monnaie l'euro et affiche l'une des croissances économiques les plus fortes de la zone OCDE : son PIB a progressé de $3,8 \%$ en 2017, soit un niveau supérieur à la moyenne de la zone OCDE, à 2,6 \%..

D'après l' Economic Survey of Lithuania 2018 (Étude économique de la Lituanie) de l'OCDE, l'économie lituanienne rattrape rapidement la moyenne de l'OCDE, le PIB par habitant du pays ayant bondi de $36 \%$ à $73 \%$ du niveau moyen de l'OCDE entre 2000 et 2017. Le chômage a chuté, passant de 9,1 \% en 2015 à 6,6 \% en 2018, selon les estimations. En outre, le rapport précise que les finances publiques se sont stabilisées grâce à d'ambitieuses réformes. 
La Lituanie dispose d'une main-d'œuvre instruite : $39 \%$ de sa population adulte (plus de 25 ans) a suivi un enseignement supérieur, sachant que la moyenne de l'OCDE se situe à $35 \%$. La notation moyenne, par la population, de la qualité des services de santé en Lituanie est passée, sur une échelle de 1 à 10, de 5,1 en 2003 à 6,3 en 2016, comme le montre l'Enquête européenne sur la qualité de vie.

La Lituanie est confrontée à différents défis, affirme la nouvelle étude économique : faire reculer des inégalités d'un niveau supérieur à la moyenne, contrer le déclin démographique et stimuler une productivité faible.

En tant que membre de l'OCDE, la Lituanie ne sera plus seule pour faire face à ces défis : elle pourra se tourner vers l'organisation multilatérale pour obtenir les éclairages, les conseils et les encouragements dont elle a besoin pour suivre la trajectoire d'une croissance inclusive et durable. De son côté, l'OCDE pourra apprendre de l'expérience de la Lituanie, qui aidera l'Organisation, comme le formule le Secrétaire général de l'OCDE Angel Gurría, " dans notre entreprise collective visant à apporter des solutions aux principaux défis économiques, sociaux et environnementaux de notre époque. L'adhésion de la Lituanie enrichira les travaux de l'OCDE grâce à l'expérience unique de ce pays dans plusieurs domaines, tandis que son adhésion à l'Organisation soutiendra les efforts que la Lituanie déploie pour améliorer le bien-être de ses citoyens. »

OL'Observateur de l'OCDE, juillet 2018

\section{Références}

Voir la liste complète des pays membres de l'OCDE : www.oecd.org/fr/apropos/ membresetpartenaires/liste-des-pays-de-l-ocde.htm

OCDE (2018), OECD Economic Surveys: Lithuania 2018, Éditions OCDE, Paris, http://dx.doi.org/https://doi.org/10.1787/eco_surveys-ltu-2018-en

OCDE (2018), OECD Reviews of Health Systems: Lithuania 2018, Éditions OCDE, Paris http://dx.doi.org/https://doi.org/10.1787/9789264300873-en

Sveikiname Lietuvą http://dx.doi.org/https://doi.org/10.1787/9789264281486-en.

Eurofound (2017), European Quality of Life Survey 2016: Quality of life, quality of public services, and quality of society, Office des publications de l'Union européenne, Luxembourg https://www.eurofound.europa.eu/fr/publications/ report/2017/fourth-european-quality-of-life-survey-overview-report. 